\title{
Mechanism to control the cell lysis and the cell survival strategy in stationary phase under heat stress
}

\author{
Rashed Noor
}

\begin{abstract}
An array of stress signals triggering the bacterial cellular stress response is well known in Escherichia coli and other bacteria. Heat stress is usually sensed through the misfolded outer membrane porin (OMP) precursors in the periplasm, resulting in the activation of $\sigma^{\mathrm{E}}$ (encoded by $r p o E$ ), which binds to RNA polymerase to start the transcription of genes required for responding against the heat stress signal. At the elevated temperatures, $\sigma^{E}$ also serves as the transcription factor for $\sigma^{H}$ (the main heat shock sigma factor, encoded by $r p o H$ ), which is involved in the expression of several genes whose products deal with the cytoplasmic unfolded proteins. Besides, oxidative stress in form of the reactive oxygen species (ROS) that accumulate due to heat stress, has been found to give rise to viable but nonculturable (VBNC) cells at the early stationary phase, which is in turn lysed by the $\sigma^{\mathrm{E}}$-dependent process. Such lysis of the defective cells may generate nutrients for the remaining population to survive with the capacity of formation of colony forming units (CFUs). $\sigma^{\mathrm{H}}$ is also known to regulate the transcription of the major heat shock proteins (HSPs) required for heat shock response (HSR) resulting in cellular survival. Present review concentrated on the cellular survival against heat stress employing the harmonized impact of $\sigma^{\mathrm{E}}$ and $\sigma^{\mathrm{H}}$ regulons and the HSPs as well as their inter connectivity towards the maintenance of cellular survival.
\end{abstract}

Keywords: Escherichia coli, Heat stress, $\sigma^{H}, \sigma^{\mathrm{E}}$, Programmed cell death (PCD), Heat shock proteins (HSPs)

\section{Background}

An assortment of physicochemical stress stimuli triggering the cellular defense related stress responsive mechanisms have been identified so far in bacteria, largely in Escherichia coli, and to certain extent in other microorganisms (Franchini et al. 2015; Munna et al. 2015; Nur et al. 2014; Nagamitsu et al. 2013; Murata et al. 2012; Valdez-Cruz et al. 2011; Rudolph et al. 2010; Caspeta et al. 2009; Noor et al. 2009a, b; Kim et al. 2007; Guisbert et al. 2007; Raivio and Silhavy 2000; Nitta et al. 2000; Hengge-Aronis 2000). The principal stress signals include nutrient exhaustion, elevated temperature, alteration in $\mathrm{pH}$ and the redox state, variations in salt concentrations, increased amount of internal reactive oxygen species (ROS), external oxidants like hydrogen peroxide $\left(\mathrm{H}_{2} \mathrm{O}_{2}\right)$,

\footnotetext{
*Correspondence: noor.rashed@yahoo.com

Department of Microbiology, Stamford University Bangladesh, 51 Siddeswari Road, Dhaka 1217, Bangladesh
}

other toxic chemicals, etc. (Munna et al. 2015; Nur et al. 2014). Such stress signals in E. coli are usually sensed by the increase in the outer membrane porin (OMP) precursors in the periplasm, which are further transduced into the cytoplasm resulting in the activation of the genes necessary for the cellular homeostatic recovery (Shenhar et al. 2009; Hayden and Ades 2008; Kim et al. 2007).

In bacteria, many stress responses are generated by the alternative sigma factors that can rapidly reprogram the necessary gene expression against various stress signals by recruiting RNA polymerase to specific subsets of stress responsive promoters in the cell (Campagne et al. 2015; Paget 2015; Murata et al. 2012; Kim et al. 2007; Gruber and Gross 2003). So far seven sigma factors have been identified that differently recognize about 2000 promoters on the E. coli genome to express around 4300 genes (Jin et al. 2013; Ishihama 1999). These factors include $\sigma^{\mathrm{D}}\left(\sigma^{70}\right.$, the "housekeeping" sigma factor, encoded by $r p o D), \sigma \mathrm{N}\left(\sigma^{54}\right.$, the nitrogen-limitation sigma factor,

\section{望 Springer}

(c) 2015 Noor. This article is distributed under the terms of the Creative Commons Attribution 4.0 International License (http:// creativecommons.org/licenses/by/4.0/, which permits unrestricted use, distribution, and reproduction in any medium, provided you give appropriate credit to the original author(s) and the source, provide a link to the Creative Commons license, and indicate if changes were made. 
encoded by rpoN), $\sigma^{\mathrm{S}}\left(\sigma^{38}\right.$, the stationary phase sigma factor, encoded by $r p o S), \sigma^{\mathrm{H}}\left(\sigma^{32}\right.$, the heat shock sigma factor, encoded by rpoH), $\sigma^{\mathrm{F}}\left(\sigma^{28}\right.$, the flagellar sigma factor, encoded by rpoF), $\sigma^{\mathrm{E}}\left(\sigma^{24}\right.$, the extracytoplasmic sigma factor, encoded by $r p o E)$, and $\sigma^{\mathrm{Fecl}}\left(\sigma^{19}\right.$, the ferric citrate sigma factor, encoded by $\mathrm{fecl}$ ). Interestingly, an extensive functional overlap has been noticed between the $\sigma$ factors: the majority of $\sigma^{\mathrm{H}}$ promoter targets overlap with those of $\sigma^{\mathrm{D}}$, and $\sigma^{\mathrm{E}}$ regulated promoters also overlaps extensively with those for $\sigma^{\mathrm{D}}$ (Wade et al. 2006). In E. coli the stress caused by elevated temperatures has long been known to be regulated by two alternative sigma factors, $\sigma^{\mathrm{H}}$ (encoded by $r p o H$ ) and $\sigma^{\mathrm{E}}$, governing the transcription of two respective heat-shock regulons to cope with protein misfolding in the cytoplasm and the extra-cytoplasm (periplasm and outer membrane), respectively (Dartigalongue and Raina 1998; Raina et al. 1995).

Indeed, a number of reports very clearly unravelled the cellular defence strategies triggered by heat stress. Present review simply compiled the information regarding the heat shock response in E. coli and attempted to decipher the cell survival strategies employing the sigma factors and the chaperon proteins at high temperature. The interesting part of the present review would be the aspects of correlation of the ROS concentrations with the formation of viable nut nonculturable (VBNC) cells triggering the induction of their lysis together with a possible cellular survival output.

\section{Cell survival employing heat-shock proteins (HSPs) in concert with sigma factors}

The transcription of the $r p o H$ gene for $\sigma^{\mathrm{H}}$ is induced at elevated temperature via the action of $\sigma^{\mathrm{E}}$ (Erickson and Gross 1989). $\sigma^{\mathrm{E}}$ is in part regulated by a cognate small RNA (as discussed later), and $\sigma^{\mathrm{H}}$ synthesis is regulated by structural change of its own mRNA molecules serving as a cellular thermometer and its activity modulated by phosphorylation (Klein et al. 2003). In E. coli, around 400 genes have been reported to be up-regulated by the transient heat shock by up-shifting the incubation temperature from 37 to $43^{\circ} \mathrm{C}$ (Gunasekera et al. 2008). Indeed, to deal with high temperature stress in E. coli, GroEL and DnaK protein amounts are largely elevated (Morimoto 2012; Morimoto et al. 2011; Guisbert et al. 2008; Kedzierska 2005). $\sigma^{\mathrm{H}}$ is principally known to regulate the transcription of the major heat shock proteins (HSPs) and molecular chaperons required for heat shock response (HSR) resulting in cellular survival. Transcription of the rpoH gene for $\sigma^{\mathrm{H}}$ is induced at elevated temperature via the action of $\sigma^{\mathrm{E}}$ (Lim et al. 2013; Murata et al. 2011). The control of the expression of HSPs has been found to be highly variable among different bacteria (Gonzalez et al. 2013; Urban-Chmiel et al. 2013; Stephanou and Latchman 2011;
Raina et al. 1995). Most of the HSPs including GroEL and DnaK, ATP-dependent proteases of Lon, HslUV, Clp and FtsH (HflB), periplasmic protease DegP, etc. are already known to be involved in protein folding, refolding, quality control and degradation, removal of damaged proteins, and are induced in response to stress (Ryabova et al. 2013; Murata et al. 2011; Gunasekera et al. 2008; Mcbroom and Kuehn 2007; Kabir et al. 2005; Ades 2004; Arsene et al. 2000; Missiakas et al. 1997).

Protein folding is known to be mediated principally by the ribosome-associated trigger factor (TF), the Hsp70 system DnaK/DnaJ/GrpE and the chaperonin system GroES/GroEL (Kumar and Sourjik 2012). While DnaK/ DnaJ/GrpE is the most adaptable chaperone system in E. coli, and GroEL and its cofactor GroES are known to be essential for cell viability (Hartl et al. 2011), another highly conserved chaperone system Hsp90 (HtpG in E. coli) is still known to be not that functional (Kumar and Sourjik 2012). Hsp100 (ClpB in E. coli) and some other small HSPs are primarily involved in refolding of the unfolded or aggregated proteins (Goeser et al. 2015; Kumar and Sourjik 2012). Interestingly, most chaperone systems are co-localized to the heat-induced protein aggregates in E. coli (Winkler et al. 2010). Besides, periplasmic protease DegP, the CpxAR (Cpx) mechanism, involvement of BaeRS (Bae), and the events of Rcs phosphorelays, the phage shock (PSP) response, and the responses generated by ppGpp in response to heat shock become functional (Alexopoulos et al. 2013; Barchinger and Ades 2013; Kumar and Sourjik 2012; Morimoto 2012; Suzuki et al. 2012; Majdalani and Gottesman 2005; Raivio 2005; Rowley et al. 2006; Ruiz and Silhavy 2005; Artsimovitch et al. 2004; Porankiewicz et al. 1999).

The controlling modulators of $\sigma^{\mathrm{H}}$ are the DnaK chaperone system together with the metallo-protease FtsH (HflB) (Arsene et al. 2000; Straus et al. 1987; Bukau 1993). Afterward the up-regulation of genes encoding the HSPs during the increase of temperature has been intensely investigated (Morimoto 2012; Valdez-Cruz et al. 2011; Akerfelt et al. 2010; Klein et al. 2003; Guisbert et al. 2004, 2008; Yura et al. 2007; Genevaux et al. 2007; Georgopoulos 2006; Wade et al. 2006; Weber et al. 2005; Gruber and Gross 2003). In order to combat against the permanently changing environmental conditions including heat shock, $E$. coli has been recently reported to employ ClpXP, ClpAP, HslUV, Lon and FtsH, for the regulated proteolysis which is required to adjust the cellular protein pool (Bittner et al. 2015). Moreover, in response to heat shock, ATP-driven proteolysis by the Clp protease $(\mathrm{Clp} / \mathrm{Hsp} 100$ chaperone family) has been reported to play a vital role in the removal of non-functional damaged proteins which is indeed in favor of cell homeostasis (Alexopoulos et al. 2013; Porankiewicz et al. 1999; Gottesman 1996). 
$\sigma^{\mathrm{S}}$, which is encoded by the $r p o S$ gene, functions as the master regulator of the general stress response, and can be activated within the range of temperature $<37-41{ }^{\circ} \mathrm{C}$ (King et al. 2014). $\sigma^{\mathrm{D}}$ is usually activated during the maximal cellular growth especially at $37-41{ }^{\circ} \mathrm{C}$. During the log phase, cells remain viable with the potential of colony formation. When the reactive oxygen species (ROS) accumulates and transforms the culturable cells into viable but nonculturable (VBNC) form, cells undergo stasis of which a major fraction undergoes $\sigma^{\mathrm{E}}$-dependent lysis (Noor et al. 2009b). Upon heat shock $\left(>42^{\circ} \mathrm{C}\right)$, most cells become non-culturable, and the $r p o E$-encoded alternative sigma factor $\sigma^{\mathrm{E}}$ and the $r p o H$-encoded classical heat-shock sigma factor $\sigma^{\mathrm{H}}$ act as the regulator of the extra-cytoplasmic HSPs (Chakraborty et al. 2014; Morimoto 2012; Murata et al. 2011).

Besides, PpiD, the outer membrane porin, (OMP) biogenesis factor with a robust peptidyl-prolyl isomerase activity, is encoded by ppiD gene which belongs to two stress regulons: the CpxR-CpxA regulon and the $\sigma^{\mathrm{H}}$ regulon (Noor et al. 2009a; Dartigalongue and Raina 1998). This is also to be mentioned that the Cpx system in cohort with $\sigma^{\mathrm{E}}$ monitor the stress signals in the cell envelope in E. coli (Matern et al. 2010; Ruiz and Silhavy 2005). Thus the possible recruitment of the HSPs by the different sigma factors, involvement of ROS generated by heat stress, and the subsequent defect in the OMP biogenesis in relation to the PpiD activity within a range of temperatures would be interesting to decipher the heat shock events in E. coli cells (Fig. 1).

\section{$\sigma^{\mathrm{E}}$-dependent programmed cell death (PCD) as the cell survival strategy}

The physiological changes in cellular behaviour and the association of sigma factors in the stress responsive events have been elaborately noticed earlier (Murata et al. 2012; Noor et al. 2009a; Erickson and Gross 1989; Raina et al. 1995). Indeed at the early stationary phase, $E$. coli cells have been noticed to undergo a decrease in the number of viable cells, and as the stationary phase progresses, interestingly cells keep sustaining their colonyforming abilities (Zambrano et al. 1993). However, at the entry of the stationary phase, in parallel with the decline in colony forming units (CFUs), cells that are viable but defective in the formation of CFUs; i.e., viable but nonculturable (VBNC) cells (Cuny et al. 2005; Desnues et al. 2003; Nystrom 2003; Nitta et al. 2000), tend to accumulate at the early stationary phase, and undergo lysis with a concomitant increase in the amounts of $\sigma^{\mathrm{E}}$ (Nitta et al. 2000; Kabir and Yamada 2005). Interestingly, such lysis has been noticed to remove the damaged cells (supported by the reduction in cell turbidity at an optical density of $600 \mathrm{~nm}$ or at $\mathrm{OD}_{600}$ ) but have no or minor impact on the cellular potential of formation of colonies (Noor et al.

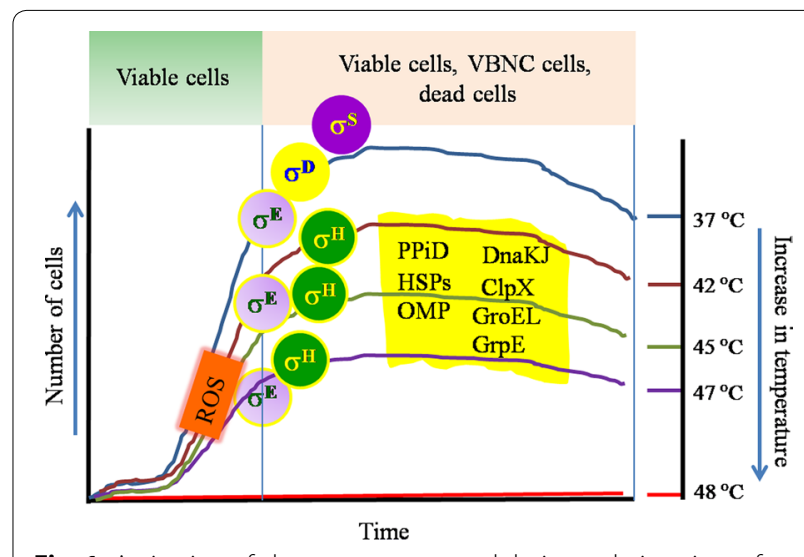

Fig. 1 Activation of chaperon system and their regulating sigma factors in Escherichia coli cells due to heat shock. rpoS encoded alternative sigma factor $\sigma^{\mathrm{S}}$, which acts as the master regulator of the general stress response is usually activated at the early stationary phase at any temperature (even below $37^{\circ} \mathrm{C}$ ). Up to the early stationary phase, usually cells are observed as viable and culturable (as shown in green box); however, during the entry into the stationary phase, a significant fraction of the total cell population become viable but nonculturable (VBNC) due to the accumulation of the reactive oxygen species (ROS). The figure shows the possible recruitment of the heat shock proteins (HSPs) in association of different sigma factors under heat stress.

The $r p o D$ encoded housekeeping sigma factor or the primary sigma factor $\sigma^{\mathrm{D}}$ together with $\sigma^{\mathrm{S}}$ transcribing most of the genes in growing cells are activated at $37-41^{\circ} \mathrm{C}$, a temperature range where cells are presumably found at their maximal growing state. Transcription of the rpoH gene for $\sigma^{\mathrm{H}}$ is induced at elevated temperature (generally at $42^{\circ} \mathrm{C}$ or more) via the action of $\sigma^{\mathrm{E}}$. Both $\sigma^{\mathrm{E}}$ and $\sigma^{\mathrm{H}}$ act as the regulator of the extra-cytoplasmic/extreme HSPs (DnaKJ, OMP, PPiD, GroEL, ClpX, GrpE). The HSPs are expected to be activated at $42-48^{\circ} \mathrm{C}$, where cells are usually completely non-culturable. Correlated reference of the narrated temperatures can be found in the text

2009a, b; Kabir et al. 2004, 2005; Nitta et al. 2000). Thus, in consistent to the earlier hypothesis (i.e., VBNC cells typically demonstrate decreased metabolic activity while on resuscitation they become culturable), the VBNC cells may be considered to define a specific program of differentiation into a long-term survival state (Oliver 2005; Bogosian and Bourneuf 2001; Villarino et al. 2000). In this context, the specific lysis of VBNC cells may be considered as the programmed cell death (PCD), with the elucidation of the mechanism of $\sigma^{\mathrm{E}}$-directed PCD (Noor et al. 2009a; Nitta et al. 2000). This mechanism might be physiologically important for $E$. coli because it can eliminate specifically the VBNC cell population.

Moreover, during survival especially under nutrient starvation, organic substances (proteins, dissolved free amino acids, and dissolved monomeric carbohydrates) are released into the surrounding medium of $E$. coil with a concomitant transition from the culturable state to the VBNC state (Arana et al. 2004). Thus, it was suggestive that the organic molecules released into the medium play a role in 
the transition from culturable to VBNC state. The mutation of the rpoS gene encoding $\sigma^{S}$ is also known to cause an increase in VBNC cells (Kabir et al. 2004). Afterward a novel point was suggested that the cellular excretion materials could be used as nutrients for the remaining population as both the culturable cells and VBNC cells were noticed in the stationary phase by Noor et al. 2009a (Fig. 2). Interestingly a culturable population was observed during stasis even upon prolonged incubation revealing the cell survival trait which may support such cell survival strategy (Noor et al. 2009a). Consistently, as stated by Murata et al. 2012, since most of cells $(\sim 60 \%)$ become VBNC in the early stationary phase, the $\sigma^{\mathrm{E}}$-directed cell lysis would eventually contribute to the removal of these damaged cells and the resultant aggregates may serve as nutrients to remaining living cells.

\section{Functional analysis of $r s e A, r s e B$, rse $C$ genes in cell survival}

One of envelope-stress responses in E. coli is performed by a regulated intra-membrane proteolysis system (Barchinger and Ades 2013; Cezairliyan and Sauer 2006) that includes the $\sigma^{\mathrm{E}}$ transcription factor, the RseA and RseB regulators, and the DegS and RseP (YaeL) proteases (Noor et al. 2009a; Cezairliyan and Sauer 2006; Kabir and Yamada 2005; Ruiz and Silhavy 2005; Ades 2004; Alba and Gross 2004; Ehrmann and Clausen 2004; Duguay and Silhavy 2004; Campbell et al. 2003). The association of $\sigma^{\mathrm{E}}$ with RNA polymerase is normally inhibited by formation of a tight complex between $\sigma^{\mathrm{E}}$ and RseA (Fig. 3). At high temperature or under other conditions that result in protein misfolding, a series of proteolytic cleavages destroy

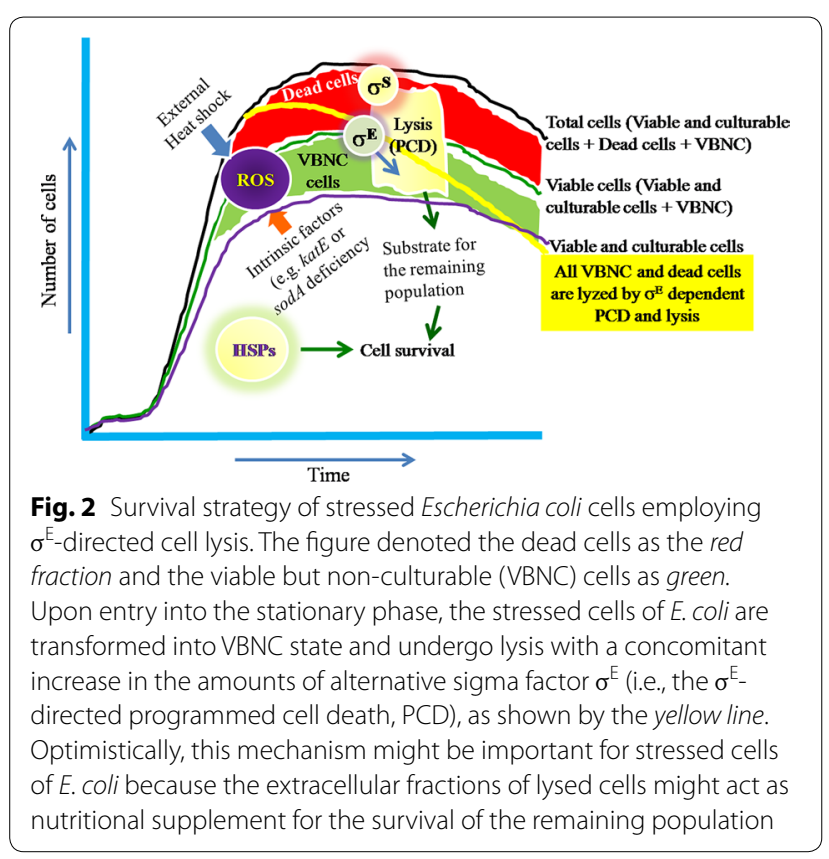

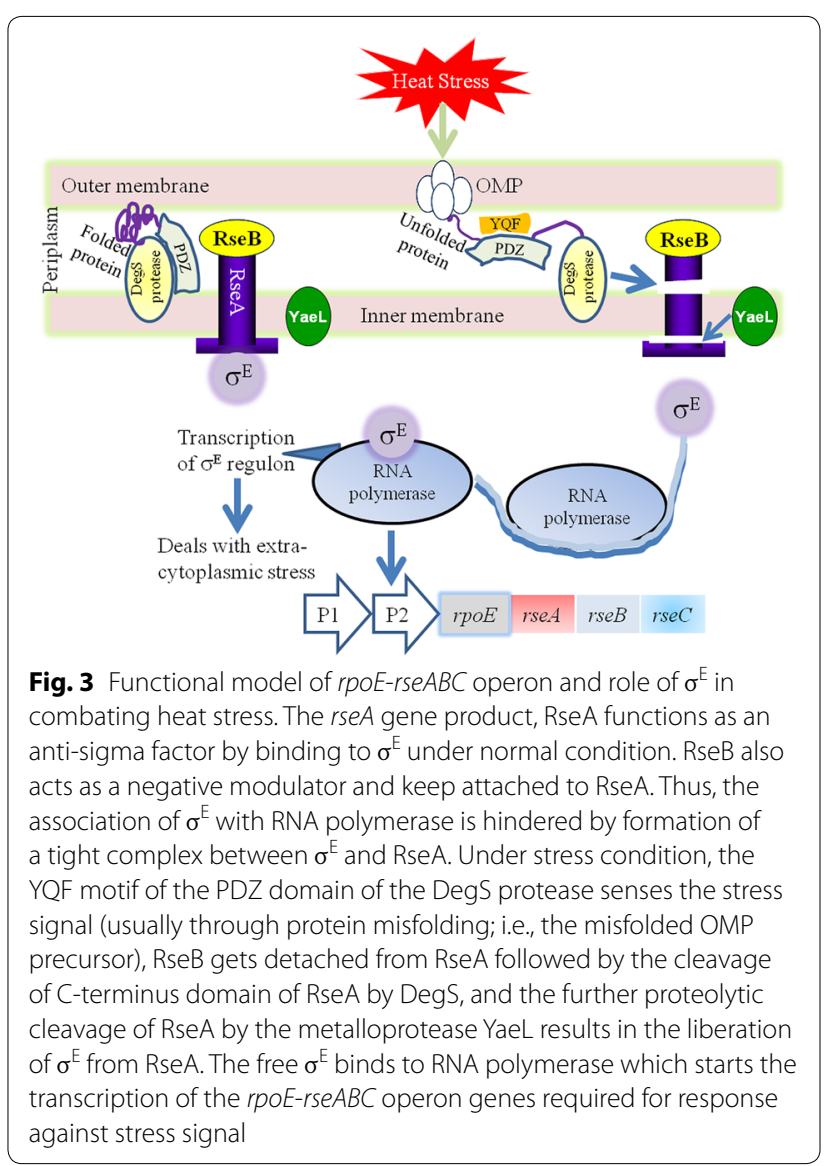

RseA and liberate $\sigma^{\mathrm{E}}$ in free form (Alba et al. 2002). DegS, which is anchored into the inner membrane by an $\mathrm{N}$-terminal transmembrane segment, is activated when the PDZ domain of DegS binds to a misfolded OMP precursor (Kim et al. 2007; Ades et al. 1999). The periplasmic $\mathrm{C}$-terminus of RseA is then cleaved by the activated DegS (Wilken et al. 2004), followed by the sequential digestion of the $\mathrm{N}$ terminus of RseA by RseP (YaeL), a membrane metalloprotease, to release the $\mathrm{N}$ terminus of RseA/ $\sigma^{\mathrm{E}}$ complex into the cytosol (Kanehara et al. 2002). The $\sigma^{\mathrm{E}}$ can be released completely from RseA, and its activity as a sigma factor is restored when the RseA fragment is removed by ClpXP protease (Kim et al. 2007; Flynn et al. 2004). The models shown in Figs. 3, 4 specifically demonstrated that the $\sigma^{\mathrm{E}}$ regulon genes deal with extracytoplasmic stress, whereas the $\sigma^{\mathrm{H}}$ regulon genes deal with the cytoplasmic stress (Kabir and Yamada 2005).

\section{Role of sodA and katE genes and the trigger of $\sigma^{\mathrm{E}}$-dependent cell lysis}

Afterward, on the basis of the suggestive data of accumulation of oxidative stresses (in the form of reactive oxygen species; i.e., ROS) at the early stationary phase 


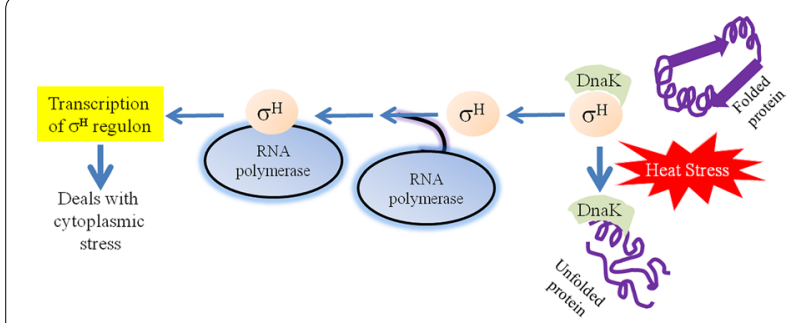

Fig. 4 Function of DnaK in association with $\sigma^{H}$ in response to heat stress. Unfolded proteins caused by heat stress are sensed by the heat shock chaperon DnaK which keeps attached to $\sigma^{H}$. Upon protein unfolding, DnaK releases $\sigma^{H}$ which in turn binds to RNA polymerase. The $\sigma^{H}$ - RNA polymerase complex transcribes genes whose products are essential to respond against the cytoplasmic stress. This is to be mentioned that the transcription of the $\sigma^{\mathrm{H}}$ (encoded by the $\mathrm{rpoH}$ gene) is induced at elevated temperature via the action of $\sigma^{\mathrm{E}}$ (encoded by the rpoE gene)

(Desnues et al. 2003; Dukan and Nystrom 1999) to cause formation of VBNC cells (Cuny et al. 2005; Nystrom $2005 a, b)$, the trigger of the lysis process was analyzed using the deletion mutant of katE (encoding catalase) and by over-expressing the $\operatorname{sod} A$ (encoding superoxide dismutase) and $k a t E$ genes (Noor et al. 2009b). The deletion mutant of $k a t E$ was noticed to result in the elevation of the amounts of intracellular ROS with a concomitant increase in VBNC cells which were further subjected to typical $\sigma^{\mathrm{E}}$-dependent cell lysis (Noor et al. 2009b). Both the amount of ROS and cell lysis level were found to be significantly reduced by the overexpression of $\operatorname{sod} A$ and katE genes (Fig. 5a). Thus, together with the knowledge of roles of HSPs under the control of $\sigma^{\mathrm{E}}$ and $\sigma^{\mathrm{H}}$ regulons (as stated earlier), the discovery of the trigger of the lysis of both VBNC and the damaged cells of $E$. coli led to model the total survival mechanism under stresses condition (Figs. 2, 4 and 5a).

\section{Heat shock and evolution of oxidative stress (through ROS generation)}

The influence of the temperature up-shift on the generation of intracellular oxidative stress has been detected earlier (Noor et al. 2013; Yamada et al. 2009), and the impulsive accretion of the ROS at the early stationary phase of bacterial growth has been monitored (Yamada et al. 2009). As stated above, our earlier study (Noor et al. 2009b) has shown that mutation in $\operatorname{sod} A$ and katE genes induced the elevated accumulation ROS, resulting in the formation of VBNC cells state, which ultimately underwent the $\sigma^{\mathrm{E}}$-directed cell lysis (Fig. 5a). Consistently when these genes were overexpressed, the ROS accumulation was noticed to be suppressed in association to the repression of the $\sigma^{\mathrm{E}}$ level (Noor et al. 2009b). The role of ROS as the trigger of such lysis involving the $\sigma^{\mathrm{E}}$ regulon a

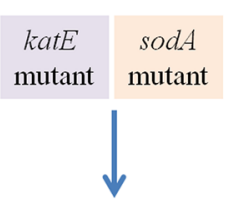
\begin{tabular}{c|c} 
Oxidative state & KatE clone \\
(Generation of ROS) & SodA clone
\end{tabular}

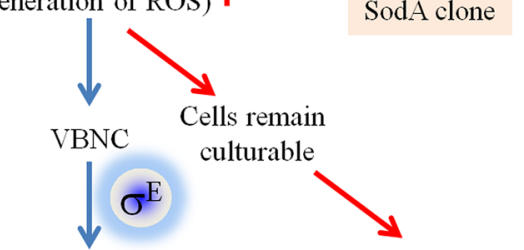

Lysis (PCD)
Suppression of $\sigma^{\mathrm{E}-}$ dependent cell lysis b

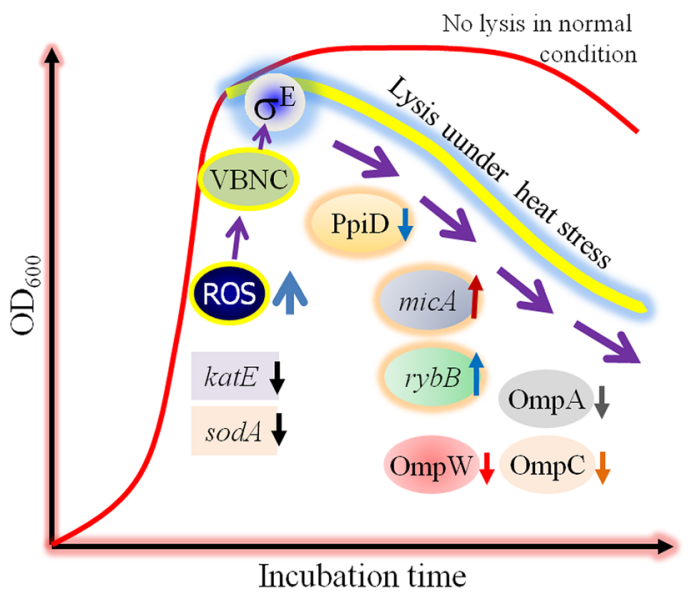

Fig. 5 Generation of heat shock and the consequent mechanism of $\sigma^{\mathrm{E}}$-dependent cell lysis. a Functional analysis of sodA and katE genes, involved in the evolution of reactive oxygen species (ROS). Mutation in sodA (encoding superoxide dismutase) and katE (encoding catalase) induces the generation of ROS which may render the viable and culturable cells to be damaged or into the VBNC state, which in turn undergoes the $\sigma^{E}$-directed lysis. Thus the defective cells are removed and only the culturable cells sustain thereby suggesting the phenomenon of programmed cell death (PCD). The idea is supported by overexpressing the sodA (SodA clone) and katE genes (KatE clone) whereby the ROS accumulation is considerably suppressed with a concomitant downregulation of the rpoE gene (encoding $\sigma^{\mathrm{E}}$ ). $\mathbf{b}$ Possible mechanism of $\sigma^{\mathrm{E}}$-dependent cell lysis whereby the role of ROS has been shown in the formation of the VBNC cells which have further undergone the lysis process with a concominant increased downregulation of peptidyl prolyl isomerise (PpiD) and the simultaneous upregulation of the micA and rybB genes encoding small RNAs. The repression of the expression of the outer membrane porins (OMPs) have also been detected which might be responsible for the impairment of the cell membrane integrity thereby rendering the cells to be lyzed 
small RNAs and the subsequent defect in OMP biogenesis proteins will be discussed later (Fig. 5b).

\section{Role of PPiD, small RNAs and OMP in $\sigma^{\mathrm{E}}$-dependent cell lysis}

While a number of ATP-dependent chaperones exist in the cytoplasm, the periplasm harbors two defined types of folding catalysts: protein disulfide isomerase (PDI) and peptidyl-prolyl cis-trans isomerase (PPIase) (Dartigalongue and Raina 1998). PPIases (PpiA, PPiD and FkpA and SurA of the parvulin family in the periplasm, and $\mathrm{PPiC}$ of the parvulin family in the cytoplasm) are known to catalyse the rapid interconversion between the cis and trans forms of the peptide bond Xaa-Pro (Dartigalongue and Raina 1998). PPiD is known to be the first member of a periplasmic folding catalyst which is regulated by the classical heat-shock sigma factor $\sigma^{\mathrm{H}}$ whereas SurA has a general chaperone-like function involved in correcting the misfolded OMP monomers whose accumulation induce the $\sigma^{\mathrm{E}}$-dependent response in the extra-cytoplasm (Lazar and Kolter 1996; Rouviere and Gross 1996).

As stated earlier, a reduction in the amounts of PpiD in the strain possessing the $\sigma^{\mathrm{E}}$-depenent cell lysis was observed (Noor et al. 2009a). Consistently, suppression of such lysis was observed upon increased expression of the ppiD gene (encoding PpiD), with the OMP folding function. Moreover, the increased expression of the $r p o E$ gene (encoding $\sigma^{\mathrm{E}}$ ) has been shown to reduce the reduction in the levels of OMPs (Murata et al. 2012). Indeed, PpiD is known to recognize the early OMP folding intermediates, and hence its over-expression suppresses OMP biogenesis defects. As stated above, the levels of PpiD were found to be severely reduced in the $r s e A$ mutants (with an increased frequency of $\sigma^{\mathrm{E}}$-depenent cell lysis) (Noor et al. 2009a). Such a reduction in the levels of PpiD could partly account for OMP reduction and hence cell lysis in $\Delta r s e A$ mutants. Therefore, the cell lysis phenotype was evidently deciphered due to reduction in the amounts of major OMPs, and conversely, the PpiD over-expression could be the cause of suppression of this lysis phenotype due to acceleration of OMP folding (Fig. 5b). The findings thus revealed an innate mechanism of cell lysis associated with the integrity of the outer membrane (OM), which is apparently impaired in the rseA mutants (Murata et al. 2012).

A second aspect of the $\sigma^{\mathrm{E}}$ response may involve the small Hfq-binding RNAs (two $\sigma^{\mathrm{E}}$-dependent small noncoding RNAs (sRNAs), MicA and RybB or Hfq chaperon) which play a major role in maintaining envelope homeostasis, rapid removal of multiple omp transcripts in response to elevated activity of the alternative sigma factor (Peng et al. 2014; Johansen et al. 2008; Vogel and Papenfort 2006). Indeed an ingenious investigation conducted by our group (Murata et al. 2012) on the consequence of sRNA (MicA and RybB, as the respective genes were under the control of $\sigma^{\mathrm{E}}$ regulon as well as the small RNAs being regulators of outer membrane protein, omp genes) on the $\sigma^{\mathrm{E}}$-dependent lysis process. Among the omp gene products, OmpA is known to be involved in the protection of cell shape and nutrient passage through the outer membrane, OmpC serves as the principal cation-selective porin, while $\mathrm{OmpW}$ is assumptive of conferring the cellular integrity (Murata et al. 2012). The micA- and rybB-disrupted mutations were found to completely repress the cell lysis. Interestingly the increased expression of micA and $r y b B$ genes or the disrupted mutants of ompA, ompC and $o m p W$ was noticed to enhance the cell lysis. Experimental demonstration by other studies also showed that the transient induction of RybB resulted in the reduced amounts of mRNA transcripts encoding OmpC and OmpW (Johansen et al. 2006). Mutation in the $r y b B$ gene resulted in the abolition of the $\sigma^{\mathrm{E}}$-mediated regulation of $о m p C$ and $о m p W$ (Johansen et al. 2006). Thus the sRNA-OMP network is of physiologically importance whereby some sRNAs act specifically on a single omp mRNA, whereas others control the multiple omp mRNA targets (Vogel and Papenfort 2006).

The possible mechanism of $\sigma^{\mathrm{E}}$-dependent lysis with the involvement of sRNA with subsequent on Omp proteins has been modelled in Fig. 5b. The model shows that the activation of $\sigma^{\mathrm{E}}$ stimulates the expression of micA and $r y b B$ genes (encoding the respective small RNAs) with a concomitant reduction in Omp proteins, which in turn causes the disintegration of the outer membrane finally resulting in cell lysis. This is to be mentioned that the expressional control of omp genes (encoding OmpC, OmpA and OmpW of outer membrane proteins) is achieved by small RNAs of micA and $r y b B$, of which genes are strictly under the control of $\sigma^{\mathrm{E}}$ (ValentinHansen et al. 2007). Interestingly MicA and RybB were found to be directly involved in cell lysis under ordinary growth conditions in the wild type strains of $E$. coli; i.e., when $\sigma^{\mathrm{E}}$ is not expressed (Murata et al. 2012). One of the possible signals for conversion of colony-formable cells to VBNC cells was identified as the accumulation of intracellular reactive oxygen species (ROS) around the beginning of stationary phase generating oxidative stress (Noor et al. 2009b). Mutations in both rpoS and $k a t E$ was found to induce $\sigma^{\mathrm{E}}$-dependent cell lysis (Noor et al. 2009b; Kabir et al. 2004). Moreover, the mutation of $\operatorname{sod} A$ (encoding superoxide dismutase) was found to significantly increase the expression of the $r p o E$ gene encoding $\sigma^{\mathrm{E}}$ (Noor et al. 2009b). Thus the involvement of ROS (either normally or due to the mutation of katE and $\operatorname{sod} A$ genes) has been shown in this model. Noor et al. 
2009a showed that the PpiD (the OMP biogenesis factor) amounts were uniquely reduced when $\sigma^{\mathrm{E}}$ levels were elevated. Such reduction in the levels of PpiD thus seems to reflect the cell lysis phenotype. Hence the PpiD has been included in Fig. 5b.

\section{Conclusion}

The present review comprehended the role of sigma factors, the heat shock proteins (HSPs), and the possible interaction between them in combating the cellular stress in $E$. coli evoked by the heat shock. The cellular events in the early stationary phase have been clearly discussed during the heat stress in terms of the elevation impact of the reactive oxygen species (ROS). Accumulation of lysis protein in course of cell incubation has been correlated with the stress resistance mechanisms. Roles of outer membrane porin (OMP), small RNAs, PPiD have clearly been demonstrated to disrupt the cell membrane integrity upon the $\sigma^{\mathrm{E}}$-directed lysis of the viable but non-culturable (VBNC) cells accumulated due to the increased ROS level due to heat stress.

\section{Acknowledgements}

Authors thank the scientist groups whose published papers have been cited in this literature review.

\section{Competing interests}

The author declares that he has no competing interests. This review has not been submitted for publication nor has been published in whole or in a part in elsewhere.

Received: 15 March 2015 Accepted: 7 October 2015

Published online: 13 October 2015

\section{References}

Ades SE (2004) Control of the alternative sigma factor $\sigma^{\mathrm{E}}$ in Eshcherichia coli. Curr Opin Microbiol 7:157-162

Ades SE, Connolly LE, Alba BM, Gross CA (1999) The Escherichia coli sigma (E)-dependent extracytoplasmic stress response is controlled by the regulated proteolysis of an anti-sigma factor. Genes Dev 13:2449-2461

Akerfelt M, Morimoto Rl, Sistonen L (2010) Heat shock factors: integrators of cell stress, development, and lifespan. Nat Rev Mol Cell Biol 11:545-555

Alba BM, Gross CA (2004) Regulation of the Escherichia coli sigma-dependent envelope stress response. Mol Microbiol 52:613-619

Alba BM, Leeds JA, Onufryk C, Lu CZ, Gross CA (2002) DegS and YaeL participate sequentially in the cleavage of RseA to activate the sigma (E)dependent extracytoplasmic stress response. Genes Dev 16:2156-2168

Alexopoulos J, Ahsan B, Homchaudhuri L, Husain N, Cheng Y-Q, Ortega J (2013) Structural determinants stabilizing the axial channel of ClpP for substrate translocation. Mol Microbiol 90:167-180

Arana I, Seco C, Epelde K, Muela A, Ferna'ndez-Astorga A, Barcina I (2004) Relationships between Escherichia coli cells and the surrounding medium during survival processes. Anton Van Leeuw 86:189-199

Arsene F, Tomoyasu T, Bukau B (2000) The heat shock response of Escherichia coli. Int J Food Microbiol 55(1-3):3-9

Artsimovitch I, Patlan V, Sekine S, Vassylyeva MN, Hosaka T, Ochi K, Yokoyama S, Vassylyev DG (2004) Structural basis for transcription regulation by alarmone ppGpp. Cell 117(3):299-310
Barchinger SE, Ades SE (2013) Regulated proteolysis: control of the Escherichia coli $\sigma(E)$-dependent cell envelope stress response. Subcell Biochem 66:129-160

Bittner LM, Westphal K, Narberhaus F (2015) Conditional proteolysis of the membrane protein $\mathrm{YfgM}$ by Fts $\mathrm{H}$ depends on a novel $\mathrm{N}$-terminal Degron. J Biol Chem 589:1346-1351

Bogosian G, Bourneuf EV (2001) A matter of bacterial life and death. EMBO Rep 2(9):770-774

Bukau B (1993) Regulation of the Escherichia coli heat-shock response. Mol Microbiol 9:671-680

Campagne S, Allain FH, Vorholt JA (2015) Extra cytoplasmic function sigma factors, recent structural insights into promoter recognition and regulation. Curr Opin Struct Biol 30:71-78

Campbell EA, Tupy JL, Gruber TM, Wang S, Sharp MM, Gross CA, Darst SA (2003) Crystal structure of Escherichia coli $\sigma^{\mathrm{E}}$ with the cytoplasmic domain of its anti- $\sigma$ RseA. Mol Cell 11:1067-1078

Caspeta L, Flores N, Perez NO, Bolivar F, Ramirez OT (2009) The effect of heating rate on Escherichia coli metabolism, physiological stress, transcriptional response and production of temperature-induced recombinant protein: a scale-down study. Biotechnol Bioeng 102:468-482

Cezairliyan BO, Sauer RT (2006) Inhibition of regulated proteolysis by RseB. Proc Natl Acad Sci USA 104:3771-3776

Chakraborty A, Mukherjee S, Chattopadhyay R, Roy S, Chakrabarti S (2014) Conformational adaptation in the E. coli sigma 32 protein in response to heat shock. J Phys Chem 118:4793-4802

Cuny C, Dukan L, Fraysse L, Ballesteros M, Dukan S (2005) Investigations of the first events leading to the loss of culturability during Escherichia coli starvation: future nonculturable bacteria form a subpopulation. J Bacteriol 187:2244-2248

Dartigalongue C, Raina S (1998) A new heat-shock gene, ppiD, encodes a peptidyl-prolyl isomerase required for folding of outer membrane proteins in Escherichia coli. The EMBO J 17:3968-3980

Desnues B, Cuny C, Gregori G, Dukan S, Aguilaniu H, Nystrom T (2003) Differential oxidative damage and expression of stress defence regulons in culturable and non-culturable Escherichia coli cells. EMBO Rep 4:400-404

Duguay AR, Silhavy TJ (2004) Quality control in the bacterial periplasm. Biochim Biphys Acta 1694:121-134

Dukan S, Nystrom T (1999) Oxidative stress defense and deterioration of growth-arrested Escherichia coli cells. J Biol Chem 274:26027-26032

Ehrmann M, Clausen T (2004) Proteolysis as a regulatory mechanism. Annu Rev Genet 38:709-724

Erickson JW, Gross CA (1989) Identification of the $\sigma^{\mathrm{E}}$ subunit of Escherichia coli RNA polymerase: a second alternative $\sigma$ factor involved in high-temperature gene expression. Genes Dev 3:1462-1471

Flynn JM, Levechenko I, Sauer RT, Baker TA (2004) Modulating substrate choice: the $\mathrm{SspB}$ adaptor delivers a regulator of the extracytoplasmic-stress response to the AAA+ protease ClpXP for degradation. Genes Dev 18:2292-2301

Franchini AG, Ihssen J, Egli T (2015) Effect of global regulators RpoS and cyclicAMP/CRP on the catabolome and transcriptome of Escherichia coli K12 during carbon- and energy-limited growth. PLoS One 10:e0133793

Genevaux P, Georgopoulos C, Kelley WL (2007) The Hsp70 chaperone machines of Escherichia coli: a paradigm for the repartition of chaperone functions. Mol Microbiol 66:840-857

Georgopoulos C (2006) Toothpicks, serendipity and the emergence of the Escherichia coli DnaK (Hsp70) and GroEL (Hsp60) chaperone machines. Genetics 174:1699-1707

Goeser L, Fan T-J, Tchaptchet S, Stasulli N, Goldman WE, Sartor RB, Hansen JJ (2015) Small heat-shock proteins, IbpAB, protect non-pathogenic Escherichia coli from killing by macrophage-derived reactive oxygen species. PLoS One 10:e0120249

Gonzalez C, Moreno-Sanchez N, Salces-Ortiz J, Perez-Guzman DJM, Serrano MM, Calvo JH (2013) Ovine HSP90AA1 expression rate is affected by several SNPs at the promoter under both basal and heat stress conditions. PLoS One 8(6):e66641

Gottesman S (1996) Proteases: and their targets in Escherichia coli. Annu Rev Genet 30:465-506

Gruber TM, Gross CA (2003) Multiple sigma subunits and the partitioning of bacterial transcription space. Annu Rev Microbiol 57:441-466

Guisbert E, Herman C, Lu CZ, Gross CA (2004) A chaperone network controls the heat shock response in E coli. Genes Dev 18:2812-2821 
Guisbert E, Rhodius VA, Ahuja N, Witkin E, Gross CA (2007) Hfq modulates the $\sigma^{\mathrm{E}}$-mediated envelope stress response and the $\sigma^{32}$-mediated cytoplasmic stress response in Escherichia coli. J Bacteriol 189:1963-1973

Guisbert E, Yura T, Rhodius VA, Gross CA (2008) Convergence of molecular, modeling and systems approaches for an understanding of the Escherichia coli heat shock response. Micro Mol Biol Rev 72:545-554

Gunasekera TS, Gsonka LN, Pally O (2008) Genome-wide transcriptional responses of Escherichia coli K-12 to continuous osmotic and heat stresses. J Bacteriol 190:3712-3720

Hartl FU, Bracher A, Hayer-Hartl M (2011) Molecular chaperones in protein folding and proteostasis. Nature 475:324-332

Hayden JD, Ades SE (2008) The extracytoplasmic stress factor, $\sigma^{\mathrm{E}}$, is required to maintain cell envelope integrity in Escherichia coli. PLoS Biol 3:e1573

Hengge-Aronis R (2000) In: Storz G, Hengge-Aronis R (eds) Bacterial stress responses. American Society for Microbiology, Washington DC, USA, pp $161-178$

Ishihama A (1999) Modulation of the nucleoid, the transcription apparatus, and the translation machinery in bacteria for stationary phase survival. Genes Cells 4:135-143

Jin DJ, Cagliero C, Zhou YN (2013) Role of RNA polymerase and transcription in the organization of the bacterial nucleoid. Chem Rev 113(11):8662-8682

Johansen J, Rasmussen AA, Overgaard M, Valentin-Hansen P (2006) Conserved small non-coding RNAs that belong to the sigmaE regulon: role in down-regulation of outer membrane proteins. J Mol Biol 364:1-8

Johansen J, Eriksen M, Kallipolitis B, Valentin-Hansen P (2008) Down-regulation of outer membrane proteins by noncoding RNAs: unraveling the CAMP-CRP- and sigmaE-dependent CyaR-ompX regulatory case. J Mol Biol 383(1):1-9

Kabir MS, Yamada M (2005) $\sigma^{\mathrm{E}}$-dependent programmed cell death in Escherichia coli In: Yamada M (ed) Survival and death in bacteria. Research Signpost, pp 55-67

Kabir MS, Yamashita D, Noor R, Yamada M (2004) Effect of $\sigma^{5}$ on $\sigma^{\mathrm{E}}$-directed cell lysis in Escherichia coli early stationary phase. J Mol Microbiol Biotechnol 8:189-194

Kabir MS, Yamashita D, Koyama S, Oshima T, Kurokawa K, Maeda M, Tsunedomi R, Murata M, Wada C, Mori H, Yamada M (2005) Cell lysis directed by $\sigma^{E}$ in early stationary phase and effect of induction of the rpoE gene on global gene expression in Escherichia coli. Microbiol 151:2721-2735

Kanehara K, Ito K, Akiyama Y (2002) YaeL (EcfE) activates the $\sigma^{\mathrm{E}}$ pathway of stress response through a site-2 cleavage of anti- $\sigma \mathrm{E}, \mathrm{RseA}$. Genes Dev 16:2147-2155

Kedzierska S (2005) Role of Escherichia coli molecular chaperones in the protection of bacterial cells against irreversible aggregation induced by heat shock. Postepy Biochem 51(2):146-153

Kim DY, Jin KS, Kwon E, Ree M, Kim KK (2007) Crystal structure of RseB and a model of its binding mode to RseA. Proc Natl Acad Sci USA 104:8779-8784

King T, Kocharunchitt C, Gobius K, Bowman JP, Ross T (2014) Global genome response of Escherichia coli O157:H7 Sakai during dynamic changes in growth kinetics induced by an abrupt temperature downshift. PLoS One 9(6):e99627

Klein G, Dartigalongue C, Raina S (2003) Phosphorylation-mediated regulation of heat shock response in Escherichia coli. Mol Microbiol 48:269-285

Kumar M, Sourjik V (2012) Physical map and dynamics of the chaperone network in Escherichia coli. Mol Microbiol 84(4):736-747

Lazar SW, Kolter R (1996) SurA assists the folding of Escherichia coli outer membrane proteins. J Bacterio 178(6):1770-1773

Lim B, Miyazaki R, Neher S, Siegele DA, Ito K, Walter P, Akiyama Y, Yura T, Gross CA (2013) Heat shock transcription factor $\sigma^{32}$ Co-opts the signal recognition particle to regulate protein homeostasis in E. coli. PLoS Biol 11:e1001735

Majdalani N, Gottesman S (2005) The Rcs phosphorelay; a complex signal transduction system. Annu Rev Microbiol 59:379-405

Matern Y, Barion B, Behrens-Kneip S (2010) PpiD is a player in the network of periplasmic chaperones in Escherichia coli. BMC Microbiol 10:251

McBroom AJ, Kuehn MJ (2007) Release of outer membrane vesicles by Gramnegative bacteria is a novel envelope stress response. Mol Microbiol 63:545-558

Missiakas D, Mayer MP, Lemaire M, Georgopoulos C, Raina S (1997) Modulation of the Escherichia coli $\sigma^{\mathrm{E}}$ (RpoE) heat-shock transcription-factor activity by the RseA, RseB and RseC proteins. Mol Microbiol 24:355-371
Morimoto RI (2012) The heat shock response: systems biology of proteotoxic stress in aging and disease. Cold Spring Harb Symp Quant Biol 76:91-99

Morimoto RI, Selkoe DJ, Kelly JW, eds (2011) Protein homeostasis Cold Spring Harbor Laboratory Press, Cold Spring Harbor, NY. In: Morley JF, Morimoto RI (2004) Regulation of longevity in Caenorhabditis elegans by heat shock factor and molecular chaperones. Mol Biol Cell 15: 657-664

Munna MS, Humayun S, Noor R (2015) Influence of heat shock and osmotic stresses on the growth and viability of Saccharomyces cerevisiae SUBSC01. BMC Res Notes 8:369. doi:10.1186/s13104-015-1355-X

Murata M, Fujimoto H, Nishimura K, Charoensuk K, Nagamitsu H et al (2011) Molecular strategy for survival at a critical high temperature in Eschierichia coli. PLoS One 6(6):e20063

Murata M, Noor R, Nagamitsu H, Tanaka S, Yamada M (2012) Novel pathway directed by $\sigma^{E}$ to cause cell lysis in Escherichia coli. Genes Cells $17: 234-247$

Nagamitsu H, Murata M, Kosaka T, Kawaguchi J, Mori H, Yamada M (2013) Crucial roles of MicA and RybB as vital factors for $\sigma^{\mathrm{E}}$ dependent cell lysis in Escherichia coli long-term stationary phase. J Mol Microb Biotechnol 23:227-232

Nitta T, Nagamitsu H, Murata M, Izu H, Yamada M (2000) Function of the $\sigma^{E}$ regulon in dead-cell lysis in stationary-phase Escherichia coli. J Bacteriol 182:5231-5237

Noor R, Murata M, Nagamitsu H, Klein G, Rain S, Yamada M (2009a) Dissection of $\sigma^{E}$ dependent cell lysis in Escherichia coli: roles of RpoE regulators RseA, RseB and periplasmic folding catalyst Ppid. Genes Cells 14:885-899

Noor R, Murata M, Yamada M (2009b) Oxidative stress as a trigger for growth phase-specific $\sigma^{\mathrm{E}}$ dependent cell lysis in Escherichia coli. J Mol Microb Biotechnol 17:177-187

Noor R, Islam Z, Munshi SH, Rahman F (2013) Influence of temperature on Escherichia coli growth in different culture media. J Pure Appl Microbiol 7:899-904

Nur IT, Munna MS, Noor R (2014) Study of exogenous oxidative stress response in Escherichia coli, Pseudomonas spp, Bacillus spp and Salmonella spp. Turk J Biol 38:502-509

Nystrom T (2003) Conditional senescence in bacteria: death of the immortals. Mol Microbiol 48:17-23

Nystrom T (2005a) Bacterial senescence, programmed death, and premeditated sterility. ASM News 71:363-369

Nystrom T (2005b) Role of oxidative carbonylation in protein quality control and senescene. EMBO J 24:1311-1317

Oliver JD (2005) The viable but nonculturable state in bacteria. J Microbiol 43:93-100

Paget MS (2015) Bacterial sigma factors and anti-sigma factors: structure, function and distribution. Biomolecules 5:1245-1265

Peng Y, Curtis JE, Fang X, Woodson SA (2014) Structural model of an mRNA in complex with the bacterial chaperone Hfa. Proc Natl Acad Sci USA 111:17134-17139

Porankiewicz J, Wang J, Clarke AK (1999) New insights into the ATP-dependent Clp protease: escherichia coli and beyond. Mol Microbiol 32:449-458

Raina S, Missiakas D, Georgopoulos C (1995) The rpoE gene encoding the $\sigma^{\mathrm{E}}$ $\left(\sigma^{24}\right)$ heat sigma $E$ (sigma 24$)$ heat shock sigma factor of Escherichia coli. EMBO J 14:1043-1055

Raivio TL (2005) Envelope stress responses and Gram-negative bacterial pathogenesis. Mol Microbiol 56:1119-1128

Raivio TL, Silhavy TJ (2000) In: Storz G, Hengge-Aronis R (eds) Bacterial stress responses. American Society for Microbiology, Washington DC, USA, pp 19-32

Rouviere PE, Gross CA (1996) SurA, a periplasmic protein with peptidyl-prolyl isomerase activity, participates in the assembly of outer membrane porins. Genes Dev 10(24):3170-3182

Rowley G, Spector M, Kormanec J, Roberts M (2006) Pushing the envelope: extracytoplasmic stress responses in bacterial pathogens. Nat Rev Microbiol 4:383-394

Rudolph B, Gebendorfer KM, Buchner J, Winter J (2010) Evolution of Escherichia coli for growth at high temperatures. J Biol Chem 285:19029-19034

Ruiz N, Silhavy TJ (2005) Sensing external stress: watchdogs of the Escherichia coli cell envelope. Curr Opin Microbiol 8:122-126

Ryabova NA, Marchenkov VV, Marchenkova SY, Kotova NV, Semisotnov GV (2013) Molecular chaperone GroEL/ES: unfolding and refolding processes. Biochemistry 78:1405-1414 
Shenhar Y, Rasouly A, Biran D, Ron EZ (2009) Adaptation of Escherichia coli to elevated temperatures involves a change in stability of heat shock gene transcripts. Environ Microbiol 11:2989-2997

Stephanou A, Latchman DS (2011) Transcriptional modulation of heat-shock protein gene expression. Biochem Res Int. doi:10.1155/2011/238601

Straus DB, William A, Walter, Gross CA (1987) The heat shock response of Escherichia coli is regulated by changes in the concentration of $\sigma 32$. Nature 329:348-351

Suzuki H, Ikeda A, Tsuchimoto S, Adachi K, Noguchi A, Fukumori Y, Kanemori M (2012) Synergistic binding of DnaJ and DnaK chaperones to heat shock transcription factor $\sigma^{32}$ ensures its characteristic high metabolic instability: implications for heat shock protein 70 (Hsp70)-Hsp40 mode of function. J Biol Chem 287:19275-19283

Urban-Chmiel R, Dec M, Puchalski A, Wernicki A (2013) Characterization of heat-shock proteins in Escherichia coli strains under thermal stress in vitro. J Med Microbiol 62:1897-1901

Valdez-Cruz NA, Ramírez OT, Trujillo-Roldan MA (2011) Molecular responses of Escherichia coli caused by heat stress and recombinant protein production during temperature induction. Bioengineered Bugs 2:105-110

Valentin-Hansen P, Johansen J, Rasmussen AA (2007) Small RNAs controlling outer membrane porins. Curr Opin Microbiol 10:152-155

Villarino A, Bouvet OMM, Regnault B, Martin-Delautre S, Grimont PAD (2000) Exploring the frontier between life and death in Escherichia coli: evaluation of different viability markers in live and heat- or UV-killed cells. Res Microbiol 151:755-768

Vogel J, Papenfort K (2006) Small non-coding RNAs and the bacterial outer membrane. Curr Opin Microbiol 9:605-611
Wade JT, Roa DC, Grainger DC, Hurd D, Busby SJ, Struhl K, Nudler E (2006) Extensive functional overlap between sigma factors in Escherichia coli. Nat Struct Mol Biol 13:806-814

Weber H, Polen T, Heuveling J, Wendisch VF (2005) Hengge R (2005) Genomewide analysis of the general stress response network in Escherichia coli: $\sigma^{\mathrm{S}}$-dependent genes, promoters, and sigma factor selectivity. J Bacteriol 187:1591-1603

Wilken C, Kitzing K, Karzbauer R, Ehrmann M, Clausen T (2004) Crystal structure of DegS stress sensor: how a PDZ domain recognizes misfolded protein and activates a protease. Cell 117:483-494

Winkler J, Seybert A, Konig L, Pruggnaller S, Haselmann U, Sourjik V, Weiss M, Frangakis AS, Mogk A, Bukau B (2010) Quantitative and spatiotemporal features of protein aggregation in Escherichia coli and consequences on protein quality control and cellular ageing. EMBO J 29:910-923

Yamada M, Noor R, Nagamitsu H, Murta M (2009) The higher temperature, the more oxidative stress and lysis in Escherichia coli. In: The 3rd International Conference on fermentation technology for value added agricultural products: Khon Kaen, pp 25-26

Yura T, Guisbert E, Poritz M, Lu CZ, Campbell E, Gross CA (2007) Analysis of sigma 32 mutants defective in chaperone-mediated feedback control reveals unexpected complexity of the heat shock response. Proc Natl Acad Sci USA 104:17638-17643

Zambrano MM, Siegele DA, Almiron M, Tormo A, Kolter R (1993) Microbial competition: Escherichia coli mutants that take over stationary phase culture. Science 259:1757-1760

\section{Submit your manuscript to a SpringerOpen ${ }^{\odot}$ journal and benefit from:}

- Convenient online submission

- Rigorous peer review

- Immediate publication on acceptance

- Open access: articles freely available online

- High visibility within the field

- Retaining the copyright to your article

Submit your next manuscript at $>$ springeropen.com 